\title{
Dihydropyrimidine Dehydrogenase Deficiency in Two Malaysian Siblings with Abnormal MRI Findings
}

\author{
Bee Chin Chen ${ }^{a}$ Rowani Mohd Rawi ${ }^{b}$ Rutger Meinsmac Judith Meijer ${ }^{c}$ \\ Raoul C.M. Hennekam ${ }^{d}$ André B.P. van Kuilenburg ${ }^{c}$ \\ ${ }^{a}$ Department of Genetics, Kuala Lumpur Hospital, Kuala Lumpur, ${ }^{b}$ School of Medical Sciences, University of \\ Sciences Malaysia, Kelantan, Malaysia; ' Laboratory of Genetic Metabolic Diseases, and ${ }^{\mathrm{d}}$ Department of \\ Pediatrics, Academic Medical Center, University of Amsterdam, Amsterdam, The Netherlands
}

\section{Key Words}

Dihydropyrimidine dehydrogenase deficiency .

MRI abnormality · Protein folding

\begin{abstract}
Dihydropyrimidine dehydrogenase (DPD) deficiency is an autosomal recessive disorder of the pyrimidine metabolism. Deficiency of this enzyme leads to an accumulation of thymine and uracil and a deficiency of metabolites distal to the catabolic enzyme. The disorder presents with a wide clinical spectrum, ranging from asymptomatic to severe neurological manifestations, including intellectual disability, seizures, microcephaly, autistic behavior, and eye abnormalities. Here, we report on an 11-year-old Malaysian girl and her 6-year-old brother with DPD deficiency who presented with intellectual disability, microcephaly, and hypotonia. Brain MRI scans showed generalized cerebral and cerebellar atrophy and callosal body dysgenesis in the boy. Urine analysis showed strongly elevated levels of uracil in the girl and boy (571 and $578 \mathrm{mmol} / \mathrm{mol}$ creatinine, respectively) and thymine (425 and $427 \mathrm{mmol} / \mathrm{mol}$ creatinine, respectively). Se-
\end{abstract}

quence analysis of the DPYD gene showed that both siblings were homozygous for the mutation c.1651G>A (pAla551Thr).

Dihydropyrimidine dehydrogenase (DPD; McKusick 274270) deficiency is a rare disorder of the pyrimidine metabolism associated with thymine-uraciluria. The clinical spectrum of patients with a complete DPD deficiency varies considerably, but the most frequently encountered neurological symptoms documented in pediatric patients are recurrent seizures and intellectual disability. Other features present are growth retardation, unusual facial morphology, microcephaly, autism, ocular malformations, and abnormal brain anatomy [Braakhekke et al., 1987; van Gennip et al., 1994; van Kuilenburg et al.,1999; Fiumara et al., 2003; Enns et al., 2004; Yau et al., 2004].

DPD constitutes the rate-limiting step in the degradation of the pyrimidine bases thymine and uracil. This $\mathrm{NADPH}$-dependent reaction converts the bases of thymine and uracil into dihydrothymine and dihydrouracil,

\section{KARGER}

E-Mail karger@karger.com

www.karger.com/msy
(C) 2014 S. Karger AG, Basel

1661-8769/14/0056-0299\$39.50/0
Bee Chin Chen

Biochemical Genetic Unit, Department of Genetics

Kuala Lumpur Hospital

Kuala Lumpur 50586 (Malaysia)

E-Mail beechinmy@yahoo.com 
respectively. These dihydropyrimidines are eventually catabolized to $\beta$-aminoisobutyric acid, $\beta$-alanine, and $\mathrm{CO}_{2}$ [Webster et al., 2001]. A complete DPD deficiency leads to excessive accumulation of thymine and uracil in urine, blood, and cerebrospinal fluid but decreased concentrations of metabolites downstream of DPD. Screening for DPD deficiency relies on the detection of these 2 important markers, uracil and thymine, by gas chromatography mass spectrometry (GCMS) or high-performance liquid chromatography (HPLC) with ultraviolet or tandem mass spectrometry [van Gennip et al., 1997; van Lenthe et al., 2000].

$\mathrm{DPD}$ deficiency is inherited in an autosomal recessive manner, and the gene DPYD is located on chromosome 1p21.3. Several mutations have been reported, with the c. $1905+1 \mathrm{G}>$ A mutation being the most frequently reported one [van Kuilenburg et al., 1999].

We report here the clinical, biochemical, and molecular findings of 2 siblings with DPD deficiency with an unusual clinical presentation.

\section{Case Report}

The 2 siblings were of Malay ethnicity, their parents were first cousins. Three older siblings were healthy, and there was no significant family history.

The first affected child, an 11-year-old girl, was born full term via spontaneous vaginal delivery with a birth weight of $3.3 \mathrm{~kg}$ and normal antenatal and postnatal history. Her development was normal until the age of 5 months when she developed fever and convulsion. Initially, there was a regression of her developmental milestones, but she subsequently progressed, albeit slowly. She was hypotonic and developed recurrent convulsions during fever at the age of 11 months but became convulsion-free by the age of 3 years. The patient was referred to the pediatric neurology clinic at the age of 5 years together with her similarly affected younger brother. Clinical examination showed microcephaly but no abnormal body morphology. She had spastic diplegia and showed a marked intellectual disability. Her brain MRI yielded normal results. She had repeated bouts of aggressive behavior and is currently attending a special education program. She can walk with support and is selfsupporting with her personal hygiene.

Her affected brother was born full term via spontaneous vaginal delivery with a birth weight of $2.7 \mathrm{~kg}$. He was well in the first few months after birth but became symptomatic at 7 months of age when he developed recurrent convulsions and subsequently developed only very slowly. Evaluation at the age of 5 years showed intellectual disability, spasticity, and microcephaly without any unusual morphological signs. MRI of his brain showed a general cerebral and cerebellar atrophy without atrophy of the pons (figs. 1, 2). The rostrum of the corpus callosum was absent, the anterior part was thin, and the anterior and posterior commissures were absent. There were no heterotopias. As a coincidental finding, a dermoid cyst was noticed in the floor of the left middle cranial

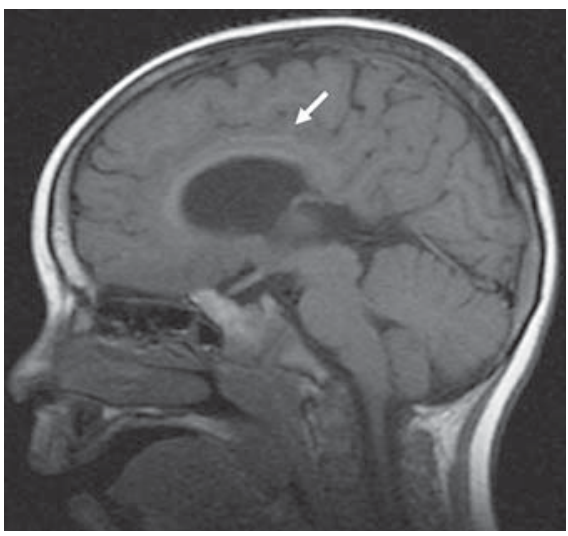

Fig. 1. MRI scan of the 5-year-old boy showing hypogenesis of the corpus callosum (arrow).

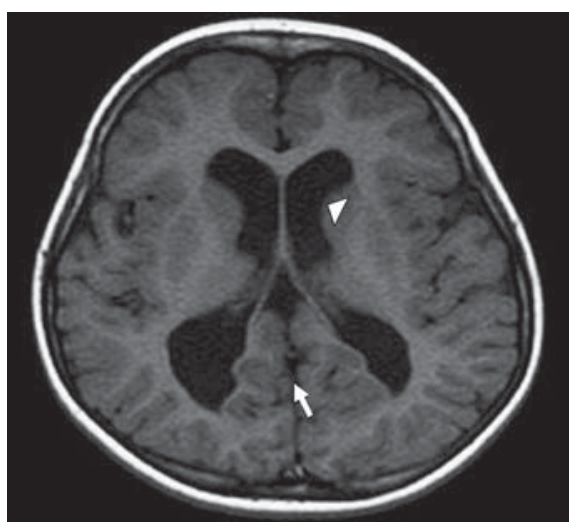

Fig. 2. MRI scan of the 5-year-old boy showing ventriculomegaly (arrowhead) and hypogenesis of the corpus callosum (arrow) (absence of splenium).

fossa. Electroencephalography showed continuously high amplitude $(400 \mu \mathrm{V})$ slow waves $(0.5-2.5 \mathrm{~Hz})$ compatible with a general encephalopathy.

In view of the parental consanguinity and the neurological abnormalities in the sibs, the family was referred to evaluate whether a genetic disorder could be present. Screening for inborn of errors of metabolism was requested at the age of 11 (sister) and 6 (brother) years.

\section{Material and Methods}

Metabolic screening included dipstick (glucose, ketone, $\mathrm{pH}$, and reducing sugars), acylcarnitine analysis, plasma amino acid and urine organic acid. Urine organic acid analysis by GCMS was performed as described before [Sweetman, 1991]. Measurement of purine and pyrimidine bases was performed using Agilent 1200 HPLC equipped with a reverse phase column and coupled with a 
multi-wavelength Diode Array Detector, as described elsewhere [Chen et al, 2012].

Molecular genetics studies were performed after written parental informed consent. EDTA-blood samples were collected from the probands, and DNA was isolated using standard methods. The DPYD mutation analysis was performed essentially as described before [van Kuilenburg et al., 2000].

\section{Results}

Initial biochemical investigations in both patients were unremarkable. The plasma amino acids profile showed significantly increased glycine $(535 \mu \mathrm{mol} / \mathrm{l}$, reference range: $125-318 \mu \mathrm{mol} / \mathrm{l})$, alanine $(853 \mu \mathrm{mol} / \mathrm{l}$, reference range: $145-475 \mu \mathrm{mol} / \mathrm{l}$ ) and proline levels (374 $\mu \mathrm{mol} / \mathrm{l}$, reference range: $40-332 \mu \mathrm{mol} / \mathrm{l})$ which may suggest lactic acidosis, mitochondrial dysfunction or an influence of medications. Serine $(281 \mu \mathrm{mol} / \mathrm{l}$, reference range: $93-176 \mu \mathrm{mol} / \mathrm{l})$ and glutamate $(232 \mu \mathrm{mol} / \mathrm{l}$, reference range: $11-79 \mu \mathrm{mol} / \mathrm{l})$ levels were also non-specifically elevated. Subsequent analysis of urine organic acids demonstrated 2 large peaks of uracil and thymine without dihydropyrimidines, which was very suggestive of DPD deficiency. The analysis of pyrimidine metabolites showed excessive excretion of uracil and thymine with mildly increased concentrations of 5-hydroxymethyluracil. The sister presented with high levels of uracil $(571 \mathrm{mmol} / \mathrm{mol}$ creatinine, reference range: $2-32 \mathrm{mmol} / \mathrm{mol}$ ); thymine (425 mmol/mol creatinine, reference range: $<1 \mathrm{mmol} /$ $\mathrm{mol})$, and 5-hydroxymethyluracil $(21 \mathrm{mmol} / \mathrm{mol}$ creatinine, reference range: $<1 \mathrm{mmol} / \mathrm{mol}$ ). Her younger brother's urine sample also showed markedly increased levels of uracil, thymine, and 5-hydroxymethyluracil: 578, 427, and $55 \mathrm{mmol} / \mathrm{mol}$ creatinine, respectively.

Molecular analysis of DPYD showed that both patients were homozygous for the mutation c.1651G $>$ A (pAla551Thr) which is a rare mutation not present in the exome variant servers (EVS) of the National Heart, Lung and Blood Institute GO Exome Sequencing Project (URL: evs.gs.washington.edu/EVS/) and in the Database of Single Nucleotide Polymorphisms (dbSNP, Bethesda; URL: http://www.ncbi.nlm.nih.gov/SNP/). In the 1000 Genomes Project database, the sequence data of 286 individuals (572 chromosomes) of East Asian Ancestry, the same ethnic background as our patients, are included, and in this population the c.1651G>A mutation has not been identified. The parents were found to be carriers of the same mutation with normal excretion levels of uracil and thymine. This mutation has been reported before [van Kuilenburg et al., 2005]. Analysis of the DPD crystal structure had suggested

Dihydropyrimidine Dehydrogenase

Deficiency in Siblings that the A551T point mutation might prevent the binding of the prosthetic group FMN and affect the folding of the DPD protein [van Kuilenburg et al., 2005].

\section{Discussion}

DPD deficiency was first proposed in 1981 in the case of a patient with thymine-uraciluria [van Gennip et al., 1981] and subsequently, Bakkeren et al. [1984] described the first case of a proven DPD enzyme deficiency in a child with unexplained convulsions and excessive excretion of urinary uracil and thymine in urine, blood, and cerebrospinal fluid. The presence of abnormal 5-hydroxymethyluracil metabolites is another important biochemical marker used to support the diagnosis of DPD deficiency. However, the precise origin of 5-hydroxymethyluracil in DPD-deficient patients is unknown. In the presence of reactive oxygen species, thymine in the DNA can be oxidized, and upon DNA repair, 5-hydroxymethyluracil is excreted in the urine [Krokan et al., 2002]. In this respect, it should be noted that increased oxidative stress has been noted in DPD-deficient patients [van Kuilenburg et al., 2006]. To date, over 50 DPD-deficient patients have been described. Most of the earlier reported cases were from Europe, in particularly from the Netherlands. The latter might be due to the fact that screening for inborn errors of purine and pyrimidine (PP) metabolism is part of a general metabolic screening program in the Netherlands. Since introducing the diagnostic service for PP metabolic disorders in Malaysia in 2007, we have identified several rare inborn errors of PP metabolism, including 4 patients $(0.16 \%)$ with DPD deficiency out of 2,433 urine samples collected from patients with suggestive clinical features such as intellectual disability, global developmental delay, seizures, microcephaly, abnormal behavior, and autism. The earlier reported cases in Malaysia were an 8-year-old Indian girl who presented with developmental delay and a 1-month-old boy who had neonatal encephalopathy with seizures [Chen et al., 2012]. The finding of 2 other individuals with a DPD deficiency in Malaysia indicates that DPD deficiency may be more common in Malaysia than previously thought.

Considerable variations in clinical symptoms have been reported in individuals with DPD deficiency, but most patients presented with neurological symptoms [van Kuilenburg et al., 1999]. However, asymptomatic individuals have also been identified in family studies and population screening [Bakkeren et al., 1984; van Kuilenburg et al., 1999]. Previously, the c.1651G>A mutation 
was detected in the parents of a deceased DPD-deficient patient who had a history of epileptic manifestation in earlier childhood, encephalopathy, prolonged hypoventilation, developmental delay and failure to thrive, and MRI abnormality [Enns et al., 2004; van Kuilenburg et al., 2005]. The clinical and biochemical findings of the present siblings are in line with those described previously for DPD-deficient patients with the exception of the brain abnormalities which have been only occasionally described [Enns et al., 2004]. The majority of the hitherto reported DPD-deficient patients is initially doing well after birth and is becoming symptomatic at 5-7 months of age with recurrent seizures and subsequently regression of the motor and cognitive development. The Malaysian girl described in this paper presented initially with hypotonia, but subsequently she and her brother had spastic diplegia. Her aggressive behavior was marked and has not often been reported in other patients with DPD-deficiency [van Kuilenburg et al., 2009]. Her MRI brain scan showed no abnormalities; her brother's scan was unusual for a DPD-deficiency patient and appears more consistently associated with $\beta$-ureidopropionase-deficient patients where generalized brain atrophy and callosal body dysgenesis are common [van Kuilenburg et al., 2012].
There is currently no effective therapy for DPD deficiency. Identification of the disorder and genetic status is important as several studies have reported that DPD deficiency and also polymorphisms in DPYD have been associated with severe (lethal) 5-fluorouracil toxicities [Wei et al., 1998; van Kuilenburg et al., 2000; Raida et al., 2001].

In conclusion, we report on 2 siblings with DPD deficiency and their unusual neurological and behavioral symptoms. We emphasize that infants and children presented with a similar neurological and behavioral phenotypes should be screened for a possible DPD deficiency.

\section{Acknowledgements}

We thank the Director General of the Ministry of Health of Malaysia for permission to publish this paper as well as the patients and clinical teams for taking part in this study. We wish to acknowledge Ms. Huzaimah, Mr. Helmi, Ms. Komalam, and Tg Rosmaliza for their technical assistance, and Dr. Julia Omar and Mr. Abas Sharudin for their assistance in the sample collection. Lastly, we thank Dr. L.H. Ngu from the Department of Genetics, Kuala Lumpur Hospital, for his clinical advice.

\section{References}

-Bakkeren JA, De Abreu RA, Sengers RC, Gabreëls FJ, Maas JM, Renier WO: Elevated urine, blood and cerebrospinal fluid levels of uracil and thymine in a child with dihydrothymine dehydrogenase deficiency. Clin Chim Acta 140:247256 (1984).

-Braakhekke JP, Renier WO, Gabreëls FJ, De Abreu RA, Bakkeren JA, Sengers RC: Dihydropyrimidine dehydrogenase deficiency. Neurological aspects. J Neurol Sci 78:71-77 (1987).

Chen BC, Thong MK, Yunus Z: Biochemical profiling of inborn errors of purine and pyrimidine metabolism by high performance liquid chromatography - a strategy to improve childhood mortality and morbidity in Malaysian children. Hamdan Medical Journal 5:363-371 (2012).

Enns GM, Barkovich AJ, van Kuilenburg AB, Manning M, Sanger T, et al: Head imaging abnormalities in dihydropyrimidine dehydrogenase deficiency. J Inherit Metab Dis 27:513-522 (2004).

- Fiumara A, van Kuilenburg AB, Caruso U, Nucifora C, Marzullo E, et al: Dihydropyrimidine dehydrogenase deficiency and acute neurological presentation. J Inherit Metab Dis 26:407409 (2003).
Krokan HE, Drabløs F, Slupphaug G: Uracil in DNA - occurrence, consequences and repair. Oncogene 21:8935-8948 (2002).

Raida M, Schwabe W, Häusler P, van Kuilenburg $A B$, van Gennip AH, et al: Prevalence of a common point mutation in the dihydropyrimidine dehydrogenase gene within the $5^{\prime}$-splice donor site of intron 14 in patients with severe 5-fluorouracil - related toxicity compared with controls. Clin Cancer Res 7:2832-2839 (2001).

Sweetman L: Organic acid analysis, in Hommes FA (ed): Techniques in Diagnostic Human Biochemical Genetics, pp 143-176 (Wiley-Liss, New York 1991).

van Gennip $\mathrm{AH}$, van Bree-Blom EJ, Wadman SK, Bree PK, Duran M, Beemer FA: Liquid chromatography of urinary pyrimidine for the evaluation of primary and secondary abnormalities of pyrimidine metabolism, in Hawk GL, Champlin PB, Hutton RF, Mol C (eds): Biological/ Biomedical Application of Liquid Chromatography III. Chromatographic Science Series, pp 285-296 (Dekker, New York 1981).

van Gennip AH, Abeling NG, Stroomer AE, van Lenthe H, Bakker HD: Clinical and biochemical findings in six patients with pyrimidine degradation defects. J Inherit Metab Dis 17:130132 (1994). van Gennip AH, Abeling NG, Vreken P, van Kuilenburg AB: Inborn errors of pyrimidine degradation: clinical, biochemical and molecular aspects. J Inherit Metab Dis 20:203-213 (1997).

van Kuilenburg AB, Vreken P, Abeling NG, Bakker HD, Meinsma R, et al: Genotype and phenotype in patients with dihydropyrimidine dehydrogenase deficiency. Hum Genet 104: 1-9 (1999).

van Kuilenburg AB, Haasjes J, Richel DJ, Zoetekouw $\mathrm{L}$, van Lenthe $\mathrm{H}$, et al: Clinical implications of dihydropyrimidine dehydrogenase (DPD) deficiency in patients with severe 5-fluorouracil-associated toxicity: identification of new mutations in the DPD gene. Clin Cancer Res 6:4705-4712 (2000).

van Kuilenburg AB, Meinsma R, Beke E, Bobba B, Boffi P, et al: Identification of three novel mutations in the dihydropyrimidine dehydrogenase gene associated with altered pre-mRNA splicing or protein function. Biol Chem 386: 319-324 (2005).

van Kuilenburg AB, Stroomer AE, Abeling NG, van Gennip AH: A pivotal role for beta-aminoisobutyric acid and oxidative stress in dihydropyrimidine dehydrogenase deficiency? Nucleosides Nucleotides Nucleic Acids 25: 1103-1106 (2006). 
van Kuilenburg AB, Meijer J, Mul AN, Hennekam RC, Hoovers JM, et al: Analysis of severely affected patients with dihydropyrimidine dehydrogenase deficiency reveals large intragenic rearrangements of $D P Y D$ and a de novo interstitial deletion del(1)(p13.3-21.3). Hum Genet 125:581-590 (2009).

-van Kuilenburg AB, Dobritzsch D, Meijer J, Krumpel M, Selim LA, et al: $\beta$-ureidopropionase deficiency: phenotype, genotype and protein structural consequences in $16 \mathrm{pa}$ tients. Biochim Biophys Acta 1822:10961108 (2012). van Lenthe $\mathrm{H}$, van Kuilenburg AB, Ito T, Bootsma $\mathrm{AH}$, van Cruchten A, et al: Defects in pyrimidine degradation identified by HPLC-electrospray tandem mass spectrometry of urine specimens or urine-soaked filter paper strips. Clin Chem 46:1916-1922 (2000).

Webster DR, Becroft DO, van Gennip AH, van Kuilenberg AB: Hereditary orotic aciduria and other disorders of pyrimidine metabolism, in Scriver CR, Beaudet AL, Sly WS, et al. (eds): The Metabolic and Molecular Bases of Inherited Diseases, ed 8, pp 2663-2702 (McGraw-Hill, New York 2001).
Wei X, Elizondo G, Sapone A, McLeod HL, Raunio $\mathrm{H}$, et al: Characterization of the human dihydropyrimidine dehydrogenase gene. Genomics 51:391-400 (1998).

Yau EK, Shek CC, Chan KY, Chan AY: Dihydropyrimidine dehydrogenase deficiency: a baby boy with ocular abnormalities, neonatal seizure and global developmental delay. HK J Paediatr 9:167-170 (2004). 